Revue d'histoire de l'enfance " irrégulière »

Le Temps de l'histoire

$11 \mid 2009$

Paroles libres, paroles captives

\title{
Chronique du Paris apache (1902-1905)
}

Jean-Jacques Yvorel

\section{(2) OpenEdition}

Journals

Édition électronique

URL : http://journals.openedition.org/rhei/3105

DOI : 10.4000/rhei.3105

ISBN : 978-2-7535-1650-2

ISSN : 1777-540X

Éditeur

Presses universitaires de Rennes

Édition imprimée

Date de publication : 1 octobre 2009

ISBN : 978-2-7535-0927-6

ISSN : 1287-2431

Référence électronique

Jean-Jacques Yvorel, «Chronique du Paris apache (1902-1905) », Revue d'histoire de l'enfance « irrégulière » [En ligne], 11 | 2009, mis en ligne le 01 octobre 2009, consulté le 04 décembre 2020. URL : http:// journals.openedition.org/rhei/3105; DOI : https://doi.org/10.4000/rhei.3105

Ce document a été généré automatiquement le 4 décembre 2020

(C) PUR 


\title{
Chronique du Paris apache (1902-1905)
}

\author{
Jean-Jacques Yvorel
}

Chronique du Paris apache (1902-1905)

2 Mémoire de Casque d'Or. La médaille de mort d'Eugène Corsy

3 Édition présentée et annotée par Quentin Deluermoz

4 Paris, Mercure de France, 2008, 245 p.

5 Dans le Paris populaire de la Belle Époque, les journaux à grand tirage et bientôt les politiques ou les experts du crime (médecins, magistrats et autres criminologues) appellent apaches les bandes de jeunes délinquants qui sévissent de Belleville à Ménilmontant ${ }^{1}$. Dans cet ouvrage dont la couverture ne porte pas de nom d'auteur, Quentin Deluermoz a réuni, présenté et annoté deux textes représentatifs de ce "moment apache".

6 Le premier, Les mémoires de Casque d'Or est déjà connu des spécialistes. C'est la revue littéraire Fin de siècle qui a recueilli et publié en 1902 les mémoires d'Amélie Élie peu après que Manda de la Courtille et Leca de Charonne se sont affrontés avec leur bande respective pour la possession de la désormais célèbre prostituée. Cependant, bien que souvent cité, ce texte n'a jamais été publié en volume. Malgré une certaine recherche du pittoresque, et le truchement du journaliste et écrivain Henri Frémont qui recueille et reformule littérairement les propos de l'égérie des Apaches, le récit d'Amélie Élie offre une ouverture sur un monde largement méconnu, celui des fractions marginales des classes populaires.

7 Le second, totalement inédit, est un manuscrit découvert, un peu par hasard, par Quentin Deluermoz, dans les archives de la préfecture de police. Il est rédigé par le gardien de la paix Eugène Corsy. Il raconte la mort d'un de ses jeunes collègues, Joseph Besse, tué par un souteneur, alors qu'il intervient pour calmer une altercation entre jeunes ouvriers devant un bar. Au-delà du dramatique événement central qui a motivé l'entrée en écriture de Corsy, La médaille de mort nous informe sur le monde des gardiens de la paix. On découvre notamment le fonctionnement de l'îlotage, pratique inspirée par le bobby londonien où les agents sillonnent continuellement un même ensemble de rues. Surtout on perçoit les valeurs officielles de ce groupe en voie de 
professionnalisation notamment la valorisation de la force physique, le culte de l'exactitude, le sens du devoir et la soumission à la hiérarchie. La mise en exergue de la dangerosité d'un métier où la mort semble roder en permanence et la haine de l'Apache, cet "autre absolu" sont les deux autres grands thèmes récurrents dans le discours de Corsy. La violence des propos de Corsy montre que l'antagonisme entre policiers et jeunes des quartiers populaires a déjà connu des phases d'acmé.

8 Si chaque récit a son intérêt propre, leur juxtaposition permet de prendre la mesure d' "un dialogue impossible entre deux groupes que tout oppose, et en même temps que tout rapproche". Dans son intéressante introduction, Quentin Deluermoz souligne tous les points de rencontre entre les deux témoignages : même rapport difficile à l'écrit, même influence des médias de masse et de leurs récits de crimes $^{2}$, même tentative de reprendre la parole, de se réapproprier les discours médiatiques. Ces deux textes montrent, comme l'écrit l'introducteur, "comment les uns et les autres, aux deux pôles de l'espace social, mobilisent expériences, situations et perceptions sociales pour tenter avec plus ou moins de succès de renforcer leur position, de la justifier, de la définir en l'opposant à l'autre, voire d'en sortir".

\section{NOTES}

1. Sur les «Apaches » outre les travaux pionniers de Michelle Perrot et de Dominique Kalifa voir Bettina Schmidt, Jugendkriminalität und Geselleschaftkrisen: Umbrüch, Dunkmodele und Lösungstrategien im Frankreich der Dritten Republik (1900-1914), Stuttgart, Frang Steiner Verlag, 2005, $590 \mathrm{p}$.

2. Sur ce point Dominique Kalifa, L'encre et le sang. Récits de crimes et société à la Belle Époque, Paris, Fayard, 1995, $351 \mathrm{p}$. 